\title{
Editorial
}

\section{The locked-in syndrome and related states}

The first descriptions of the locked-in syndrome are found in general, non-medical literature. A. Dumas the father wrote in 1844 his famous novel Monte-Cristo, in which Mr Noirtier de Villefort suffers from a stroke, with all the symptoms of the locked-in syndrome. Communication with him was through a dictionary where his son pointed out letters and words, and the father nodded or moved his eyes. In 1868 Emile Zola described Thérèse Raquin, heroine of the novel bearing her name, who had a stroke complicated by quadriplegia and mutism, but whose eyes moved and were alert. A century later, Plum and Posner (1972) introduced the term locked-in syndrome (LIS). Patients with LIS are tetraplegic, mute but alert and fully conscious. They can communicate through blinking or nodding.

The LIS is different from coma, vegetative state, akinetic mutism or catatonia (Adams and Victor, 1981; Walton, 1977, 1985). Coma is a state of unarousable unresponsiveness, in which the ascending reticular formation in the brain stem and diencephalon is damaged. Coma means complete unconsciousness; between coma and full consciousness there are states which differ not only in degree, but also in quality (Walton, 1977). Lethargy is a state of drowsiness and indifference, in which increased stimulation may be needed to obtain a response. In stupor, the patient can only be aroused by vigorous and continuous stimuli. Akinetic mutism (AM) is another state of stupor with general muscular relaxation; the eyes appear alert to moving objects, but strong afferent stimuli are incapable of arousing the patient. AM was first described by Cairns et al. in 1941, in a patient with an epidermoid cyst of the third ventricle. The patients respond reflexively to painful stimuli and may make semi-purposeful movements. The condition may be caused by third ventricle tumours, trauma, infection, anoxia or vascular lesions (Pearce, 1987). Recently, AM developed in a bone marrow transplant recipient, following total body irradiation and amphoterocin B chemoprophylaxis (Devinsky et al., 1987). AM was also recently described in a patient with AIDS, treated with prochlorperazine and droperidol, who developed a neuroleptic malignant syndrome (AM, resting tremor, cogwheel rigidity, and elevated CPK levels) (Bernstein et al., 1986). The most common disorder of behaviour occurring with mutism is catatonia; but schizophrenia, affective disorders, conversion reaction and other conditions may be associated with mutism (Altschuler et al., 1986). The differential diagnosis of AM and catatonia is not easy (Strub, 1985).

In the LIS the patient is fully aware of his surroundings, alert but tetraplegic, aphonic, anarthric, so that he can communicate only through blinking or other ocular movements. This is related to bilateral destruction of the medulla or basis pontis (Walton, 1977, 1985; Adams and Victor, 1981). This lesion spares the pathways of somatic sensation and the non-specific ascending system of nerves and fibres responsible for arousal and wakefulness, but interrupts the corticobulbar and corticospinal tracts, depriving the patient of speech. LIS usually results from infarction tumour (Cherrington et al., 1976), haemorrhage trauma (Britt et al., 
1977), or demyelination. LIS may follow chronic alcoholism, with nutritional, fluid and electrolyte disturbances, and rapid correction of hyponatremia (Nielsen, 1987; Illowsky and Lavreno, 1987; Mozes et al., 1986).LIS can result from vascular strokes (Karp et al., 1974; Poulsen et al., 1987). The electroencephalogram is usually normal or universally slow in LIS (Markand, 1981); and the CT scan may reveal destruction of the medioventral portion of the pons (Tijssen and Terbruggen, 1986). Abnormal brain stem auditory evoked potential were also recorded in this syndrome (Seales et al., 1981).

Neuropathological studies show brain stem lesions: bilateral necrosis of the basis pontis, involving the rostral and middle segments (Reznik, 1983).

Long term survival is rare. A follow-up report of more than a year in 27 cases was published recently (Haig et al., 1987). Recovery is very rare, most of the patients are at home, dependent upon others in most of the activities of daily living, or communicate through electronic devices, computers, printers and synthetic voice machines triggered by sensitive switches, EMG devices or eye gaze sensors. A programme of intensive rehabilitation should be considered in all LIS patients (vascular and non-vascular) in order to assist the patients to accomplish the highest possible level of functional ability (Ebinger et al., 1985; Patterson and Grabois, 1986; McGuire et al., 1987).

Abraham Ohry, MD
Neurological Rehabilitation Department
Sheba Medical Center
Tel Hashomer 52621
ISRAEL

\section{References}

Adams RD, Victor M 1981 Principles of Neurology, 2nd edn. McGraw-Hill, New York, p 233.

Altschuler LL, Cummings JI, Mills MJ 1986 Mutism: review, differential diagnosis and report of 22 cases. American fournal of Psychiatry 143:1409-1414.

BERNSTEIN WB, SCHEROKMAN B 1986 Neuroleptic malignant syndrome in a patient with acquired immuno deficiency syndrome. Acta Neurologica Scandinavica 73:636-637.

Britt RH, HerRICK MK, Hamilton RD 1977 Traumatic locked-in syndrome. Annals of Neurology 1:590-592.

Cairns H, Oldfield RC, Pennybacker JB, Whitteridge D 1941 Akinetic mutism with an epidermoid cyst of the third ventricle. Brain 64:273-290.

Cherrington M, Stears J, Hodges J 1976 Locked-in syndrome caused by a tumor. Neurology 26:180-182.

Devinsky O, Lemann W, Evans AC, Moeller JR, Rottenberg DA 1987 Akinetic mutism in a bone marrow transplant recipient following total-body irradiation and amphotericin B chemoprophylaxis. Archives of Neurology 44:414-417.

Ebinger G, Hugghens L, Corne L, Aelbrecht W 1985 Reversible locked-in syndromes. Intensive Care Medicine 11:218-219.

HaIg AJ, KaTZ RT, SAHGal V 1987 Mortality and complications of the locked-in syndrome. Archives of Physical Medicine and Rehabilitation 68:24-27.

ILLOWSKY BP, LAVRENO R 1987 Encephalopathy and myelinolysis after rapid correction of hyponatremia. Brain 110:855-867.

KARP JS, HURTIG HI 1974 Locked-in state with bilateral midbrain infarcts. Archives of Neurology 30:176-178.

MARKAND ON 1976 Electroencephalogram in locked-in syndrome. Electroencephalography and Clinical Neurophysiology 40:529-539.

McGuire TJ, Hodges DL, MEdhat MA, RedFord JB 1987 Transient locked-in syndrome and phenobarbital. Archives of Physical Medicine and Rehabilitation 68:566-567.

MOZES, B, PINES A, WERNER D et al. 1986 Thiazide-induced hyponatremia: an unusual neurologic course. Southern Medical fournal 79:629-631. 
NIELSEN JM 1987 Central pontine myelinolysis complicating hyponatremia. The Medicalfournal of Australia 146:492-493.

PATTERSON JR, GREBoIs M 1986 Locked-in syndrome: A review of 139 cases. Stroke 17:758-764.

PEARCE JMS 1987 The locked-in syndrome. British Medical fournal 294:198-199.

POUlSEN VJ, KJAER L, ARLIEN-SOBORG P 1987 Locked-in syndrome following cervical manipulation. Acta Neurologica Scandinavica 76:486-488.

Plum F, Posner JB 1972 The Diagnosis of Stupor and Coma, 2nd edn. FA Davis, Philadelphia.

REZNIK M 1983 Neuropathology in seven cases of locked-in syndrome and alcoholism - a preventable complication. The Medicalfournal of Australia 146:487-490.

Seales DM, Torkelson RD, Shuman RM, Rossiter VS, Spencer JD 1981 Abnormal brainstem auditory evoked potential and neuropathology in locked-in syndrome. Neurology 31:893-896.

STRUB RL 1985 Mental disorders in brain diseases. In: Fredricks JAM (ed) Handbook of Clinical Neurology Vol 46, Neurobehavioral disorders. Elsevier, Amsterdam, pp 413-441.

TiJssen CC, TeRBRUgGen JP 1986 Locked-in syndrome associated with ocular bobbing. Acta Neurologica Scandinavica 73:444 446.

Walton JN 1977 Brain's Diseases of the Nervous System, 8th edn. Oxford University Press, New York, pp 1158-1159.

Walton JN 1985 Brain's Diseases of the Nervous System, 9th edn. Oxford University Press, New York p 645. 